\title{
Medical Electives in Sub-Saharan Africa: A 15-Year Student/ NGO-Driven Initiative
}

\author{
Gianluca Quaglio 1,2,3 - Donald Maziku ${ }^{4}$ Marta Bortolozzo ${ }^{5}$. Nicoletta Parise ${ }^{6}$. Chiara Di Benedetto ${ }^{2}$. \\ Alice Lupato $^{5} \cdot$ Chiara Cavagna $^{2} \cdot$ Ademe Tsegaye $^{7} \cdot$ Giovanni Putoto $^{2}$
}

Accepted: 26 October 2021 / Published online: 11 November 2021

(c) The Author(s), under exclusive licence to Springer Science+Business Media, LLC, part of Springer Nature 2021

\begin{abstract}
Medical schools are developing global health programmes, and medical students are requesting global health training and creating opportunities when these are not provided by medical schools. This article described the Wolisso Project (WP), a medical experience on clinical electives in Sub-Saharan Africa, driven by a collaboration between a student organisation and a Nongovernmental Organization (NGO). Preclinical medical students spent 4 weeks as part of a multidisciplinary medical team in Africa. Post-elective questionnaires were administered to all subjects who participated in the project. Of all, 141 students responded to the questionnaire. The participants came from 30 Italian universities. The main difficulties reported are due to the lack of resources for the exercise of the medical activity, and difficulties related to language and communication. The African experience had a positive impact on the progress of the studies upon return, with an increase in determination and motivation. The experience had also positive influences on the future professional choices and carriers. The experience seems to contribute not only to the professional growth, but also to the personal development. A key factor in the positive outcomes of this experience is it being implemented by an NGO with long-term working relationships with the African populations. Another is that the project is carried out in health facilities where NGO staff have been working for a long time. These factors reduce the potential risks connected with this type of experience. They ensure a satisfactory level of supervision, the lack of which has been a serious problem in many similar experiences. A well-structured, mentored experience in international health can have a positive impact on preclinical students' attitudes, including their compassion, volunteerism, and interest in serving underserved populations. Only a small number of Italian universities facilitate pregraduate medical elective experiences in LMICs. The WP seems to be attempting to compensate for the lack of international experience in LMICs offered by universities. Italian medical schools should incorporate changes in their curricula to train socially responsible physicians.
\end{abstract}

Keywords Medical elective $\cdot$ International health $\cdot$ Sub Saharan-Africa $\cdot$ Global health

Disclaimer The views expressed in this publication are the sole responsibility of the authors and do not necessarily reflect the views of the affiliated organisations.

Gianluca Quaglio

gianluca.quaglio@europarl.europa.eu

1 European Parliamentary Research Services, (EPRS), European Parliament, Rue Wiertz, 60, B-1047 Brussels, Belgium

2 Operational Research Unit, Doctors with Africa-Cuamm, Padua, Italy

3 Department of International Health, Faculty of Health, Medicine, and Life Sciences, Care and Public Health
Research Institute (CAPHRI), University of Maastricht, Maastricht, The Netherlands

4 Tosamaganga Council Designated Hospital, Iringa, United Republic of Tanzania

5 Italian Medical Students Association (SISM), Padova, Italy

6 Department of Statistical Sciences, Padua University, Padova, Italy

7 Saint Luke Hospital, Wolisso, Ethiopia 


\section{Introduction}

An editorial published more than 50 years ago in JAMA stated that, "if, as a routine, young American doctors were encouraged to spend some months working in a developing country before they became tied to the responsibilities of practice, the result could only be better medicine at home and abroad" [1]. This statement is more relevant than ever in a time of globalisation, where the intensifications of movement of people, products, and services among countries affect many aspects of public health, as the COVID19 pandemic has dramatically shown [2]. To provide global health training and facilitate international clinical experiences for medical students has now become a necessity, because mainstream medical education remains largely focused on national — as opposed to global — health issues [3]. Electives often provide students with their first exposure to international health [4], offering participants opportunities to develop clinical skills and to explore new cultures. A Lancet editorial describes how, "no other part of the [medical] course transforms students so rapidly and profoundly' [5].

Although a significant proportion of students either remain near home or travel to developed countries, medical students are increasingly travelling further afield to low- or middle-income countries (LMICs) to undertake electives. In addition to the opportunity to discover a new country, and experience medicine in a different cultural environment, a number of benefits have been identified to explain the growth in popularity of medical electives in LMICs [6]. These include the gaining of greater experience in working in under-resourced communities, increased diagnostic skills where the use of medical technologies is extremely limited, and a greater appreciation of public health measures and primary care medicine [7-12].

Like any global health intervention, this largely unidirectional flow of students travelling from high-income countries to LMICs also requires critical evaluation of possible unintended consequences [13]. A key concern is whether students will take on excessive clinical responsibility, practising beyond their competence, which raises ethical and professional issues $[14,15]$. Another concerns the health risks associated with electives [16]. Another issue is that electives can be perceived as a means to fulfil the students' own ends rather than to serve the needs of their host communities [17], raising concerns about the medical elective impact on resource-constrained host communities $[18,19]$.

In 2010, the Working Group on Ethics Guidelines for Global Health Training (WEIGHT) developed guidelines for best practices in IMEs to minimize possible burden on host institutions. These guidelines included recommendations for (i) structured, long-term, mutually beneficial partnerships that consider local needs and priorities; (ii) preparatory training; (iii) adequate supervision and the collection of data aimed at assessing the benefits and harms of medical electives on communities and patients [20].

In addition, it must be added that historic legacies (e.g. colonialism and the exploitation of people) permeates the design and the functioning of public health systems, resulting in ethnic, structural and racial inequities within and between communities and countries [21]. Therefore, the notion of global health, being drafted and designed mostly by western people and institutions, has been severely questioned [22]. As a result, the current experiences and practices of the international electives have come under a severe scrutiny $[23,24]$. A new paradigm demands that global health practitioners meaningfully engage with the global and local structures that drive health imbalances in terms of knowledge, power, funds and leadership [25].Instead of focussing only on biomedical and clinical capacity, it should be oriented more on multidisciplinary approaches and transformative learning practices around social inequity at institution and community level [26].

Smith and Weaver have shown how a well-structured, mentored, medical elective experience in developing countries can have a positive impact on preclinical student attitudes [27]. Dowell and Merrylees observe [28], 'one way of achieving such structure is through establishing and developing institutional partnerships between the sending and receiving institutions'. They also emphasise that, 'the continuity of student presence provided by a partnership allows more comprehensive student preparation', and that the preparation of students for electives, 'is easier to organise and of more direct relevance for groups of students who are going to the same place as part of an institutional partnership. Continuity can also allow opportunities to expand the student contribution through, for example, student fundraising and support for specific projects'.

This present paper sets out the experience of Italian medical students on clinical electives in Sub-Saharan Africa, in an initiative called the Wolisso Project (WP) [29], driven by a collaboration between the Italian Medical Students Association (SISM) [30] and the Non-governmental Organization (NGO), Doctors with Africa-CUAMM (DwA) [31]. DwA works to improve the health of African populations, providing healthcare services open to all. The organisation has been working in Africa since 1950 and as its main strategy has adopted the strengthening of health systems to build resilient communities in Africa [32]. It also works by promoting learning environments and knowledge about global health issues.

The WP is governed by a memorandum of understanding, signed by DwA and SISM. It takes its name from the 
city of Wolisso in Ethiopia, which was the location for the first medical elective site that hosted students. Later, the project expanded to include the Tosamaganga hospital in Tanzania, but the name of the project remains unchanged. The project offers undergraduates the chance to undertake a medical elective in one of the two African sites. It also aims at kindling a desire to work in the international medical field. We report here the 15years' experience of the WP, through the results of a survey distributed to all subjects who participated in the project.

\section{Methods}

DwAis present in eight Sub-Saharan African countries: Angola, Central African Republic, Ethiopia, Mozambique, South Sudan, Uganda, Sierra Leone, and Tanzania. It operates through expatriated and local health professionals, technicians and administrative staff, providing support to hospitals, health districts (for public health activities, mother-child care, infectious diseases), rehabilitation centres, nursing schools, and medical universities (in Uganda, Mozambique and Ethiopia) [31]. DwA has a long-term working relationship with African populations and is well integrated into a number of communities. The WP is being carried out in health facilities where DwA staff have been working for many years: this allows for understanding the conditions of the local health system in relation to social determinants and local healthcare seeking behaviours. Knowledge of health seeking behaviours brings an understanding of how people use the health care systems in their specific socio-cultural, economic, and demographic context. The knowledge of social determinants while delivering services helps in developing health promotion interventions and in suggesting appropriate health policies to decision-makers.

The SISM, a member of the International Federation of Medical Students Associations (IFMSA) [33], provides training to medical students through national and international initiatives. The objective is to improve the clinical skills of future physicians and raise awareness of ethical and social aspects of the medical profession from a global health perspective [30]. The members of the association are committed to operating in an independent, intercultural and collaborative way of working, based on equality, transparency, and legality, with the aim of improving the knowledge levels and skills of medical students. The association is organized into 39 local committees. Each of them is related to one or more Faculties of Medicine and Surgery, often having physical offices in the academic locations. The association organises at least two national meetings per year. The main governing bodies are the National Council and the Executive Council.

\section{Participants' Selection}

The selection concerns medical students attending the year 5 and year 6 as well as newly graduated doctors. The selection is and managed by the SISM project staff (on average 10/12 people), which provides information, opens calls, collects applications, and selects students. The evaluation of applications is based on guidelines established by the SISM, with a final verification in agreement with DwA and the African local health authorities. In the selection process, scores are ascribed on (i) expectations-10 point; (ii) motivation-10 points; (iii) previous international medicine experiences (also as active engagement as volunteers in national and local projects supporting health service for migrants and marginalised people) - 3 point; (iv) collaboration within the SISM association (coverage of assignments, project organization, involvement in working groups) - maximum 3 point; (v) attendance of the online global health activities provided by DwA-1 point; (vi) collaboration with $\mathrm{DwA}-1$ point. The duration of the elective is 4 weeks and in each hospital students can choose in what specialty/department they want to do their elective.

\section{Pre-departure and Post Departure}

The pre-departure training is also organised by SISM. It mainly concerns information on ethical, practical, and attitudinal aspects, which need to be considered in this type of experience. The pre-departure phase provides a description of the socio-political, economic, and cultural context in Ethiopia and Tanzania [29]. Students are put in contact with the DwA staff in order to get pre-departure information. Any costs incurred, such as for travel and accommodation, are covered by the students. Occasionally, DwA provides funding support for the initiative. DwA offers training courses on global health and health cooperation in many Italian universities, in collaboration with SISM. For example, in 2019, 27 courses in 23 Italian universities were organised [34].Students participating in medical electives have the opportunity to attend these training courses on a voluntary basis. However, the participation in these courses is considered an added value during the selection phase for the project [35]. At the end of the WP experience, students complete an evaluation form and attend debriefing sessions with DwA staff. Students are also encouraged to elaborate on their experience through reflective writing, published on the DwA website [36] and are invited to share their experiences at the WP annual meeting.

\section{Setting and On-site Activities}

Initially, since its inception in 2005, the experience was involved only with the Wolisso hospital in Ethiopia; later 
in 2010 it was extended to the Tosamaganga hospital in Tanzania. For different reasons, the site in Tanzania was closed-partially or totally-in 2011 and 2017. The Wolisso hospital is a referral, non-profit facility located in Wolisso town, $115 \mathrm{~km}$ from Addis Ababa. Wolisso is the capital of the Southwest Shoa Zone (SWSZ) in the Oromiya region. The SWSZ has a population of about 1.1 million (Table 1). The Tosamaganga hospital is located in the district of Iringa DC, Tanzania. This is a rural area $500 \mathrm{~km}$ from Dar Es Salaam, the county's largest city. DwA has supported the hospital in terms of governance and human resources for more than 30 years. The Tosamaganga hospital serves an estimated population of 265,000 (Table 1).

In these two African hospitals students do not have a single tutor but are supervised by all the staff, including expatriated and local health personnel. Under supervision, the students are encouraged to develop clinical learning through observation, participation in the clinical decision making process, participation in bedside visits, collegial discussion of clinical cases, and meetings with nurses and relatives. All these activities are carried out without a direct involvement in diagnosis and therapy. Students do not intervene on patients except for simple nursing activities, and this is on a voluntary basis, and again always under supervision.

In the strategic plan of DwA [32], the continuity of care between hospitals, peripheral health centres, and communities is key to the organization's activities. Accordingly, in addition to hospital activities, students carry out visits to peripheral health centres and communities. These visits are mediated by government health staff (District Health Management Teams and Community Health Workers). The meetings with communities, especially with women, are aimed at learning about health care seeking behaviours and the cultural, geographical, and financial barriers that prevent populations from accessing services. The goal is to foster among students the ability to listen to local populations and the ability to raise the right questions in situations with limited resources, analysing reality from a public health and global health perspective. Further group discussions focus on social determinants and communities as a subject of health. Engagement with these issues is further deepened by involving the students with the operational research on clinical and public health issues carried out in the field.

\section{Data Collection}

The study used a mix of quantitative and qualitative methods to collect and analyse data. The survey was electronically distributed to all individuals who participated in the project. After an initial invitation to take part, two followup reminders were sent out. Participants were informed that the survey would be used for research purposes. The Ethics Committee of DwA-CUAMM approved the study and the data collection was performed in accordance with relevant guidelines and regulations. Participants were assured of their anonymity. The questionnaire comprised four domains: (i) general information: age, gender, university of provenance and prior experience in LMICs; (ii) obstacles encountered by students during the experience; (iii) impact that the experience had on medical studies and future clinical approaches; (iv) reflections, wherein the survey asked how the experience contributed to personal and professional growth, and about students' availability for future experiences in LMICs (Annex I).

\section{Data Analysis}

Each item of the questionnaire has been described using the univariate analysis. Categorical variables are summarised using frequency tables, and ordinal variables are summarised using quartiles. In the second stage, bivariate analysis was conducted with the aim of identifying any associations between variables or differences between groups of respondents. Cross tables and Pearson's chisquare test were used to evaluate the associations between categorical variables. Paired t-tests were used to see if the means of two paired measurements (pre-departure score and post-departure score, used by respondents to describe their opinions and attitudes) were different. A value of $\mathrm{p}<0.05$ was considered significant. Statistical analyses were performed using SPSS (SPSS Inc., United States). We extracted de-identified free-text data from the online repository and completed a qualitative thematic analysis, using the frameworks of conventional qualitative content analysis and inductive category development. A trained researcher (N.P.) independently coded responses and recorded emergent themes. A second experienced qualitative researcher (G.Q.) used the established themes to independently code the same written transcripts.

Table 1 Sites of electives undertaken by participants and some hospitals indicators (year 2019)

\begin{tabular}{llllllllll}
\hline Hospital & Population served & Beds & Out patients & Admissions & Antenatal visits & Births & Vaccination & Total staff & Qualified staff \\
\hline Tosamaganga & 687460 & 165 & 25850 & 6931 & 1661 & 2708 & 8298 & 165 & 109 \\
Wolisso & 1198149 & 200 & 78716 & 14742 & 8244 & 3687 & 5552 & 353 & 228 \\
\hline
\end{tabular}




\section{Results}

\section{General Information}

Figure 1 shows the number of applications and departures during the 2005-2019 study period. The WP received an average of 92 requests per year, with a substantial increase over the years, but with a reduction in 2019 (probably because the Tosamaganga site was temporarily closed and the students were less attracted to having only one site available). In the same period, there were on average 22 departures per year. Of the 333 students who took a medical elective during the study period, 257 were contacted for the survey. (For the others the email address was invalid). Of those, 141 responded (a 55\% response rate). The majority of the questionnaires (76 subjects, 54\%) were completed by those who had had the elective experience in the last 4 years (2016-2019). The majority of students were female and carried out the electives at Wolisso hospital. At the time of departure, most of the participants were Year 5 or Year 6 medical students. The participants came from 30 Italian universities. The majority had previously carried out voluntary activities: however, the majority had never been to Africa before (Table 2).

\section{Obstacles During the Experience}

Although the students were not directly involved in diagnostic and therapeutic activities, the biggest difficulties reported are mainly the lack of resources for the medical practice (55\% of subjects), problems related to language and communication
Table 2 General information of participants

\begin{tabular}{lr}
\hline General information & N. $(\%)$ \\
\hline Sex & $117(83)$ \\
Female & $24(17)$ \\
Male & \\
Location & $95(67)$ \\
Wolisso & $46(33)$ \\
Tosamaganga & \\
Position at the time of departure & $62(44)$ \\
5-year medical students & $25(18)$ \\
6-year medical students & $54(38)$ \\
Already graduates but not yet residents & \\
Medical practice before departure & $77(55)$ \\
Yes & $64(45)$ \\
No & \\
Previous voluntary activities & $108(77)$ \\
Yes & $33(33)$ \\
No & \\
In Africa before & $95(67)$ \\
Never & $24(17)$ \\
As a volunteer & $22(16)$ \\
As a tourist &
\end{tabular}

(35\% of respondents) and different systems of values (30\%). A minority also reported as difficulties the lack of hygiene (12\%) and the distance from relatives (10\%) (Fig. 2). In the open question that asked to report other relevant obstacles, few respondents added difficulties in relations with local staff, the lack of a person to coordinate activities and difficulties due to the political situation of the country.

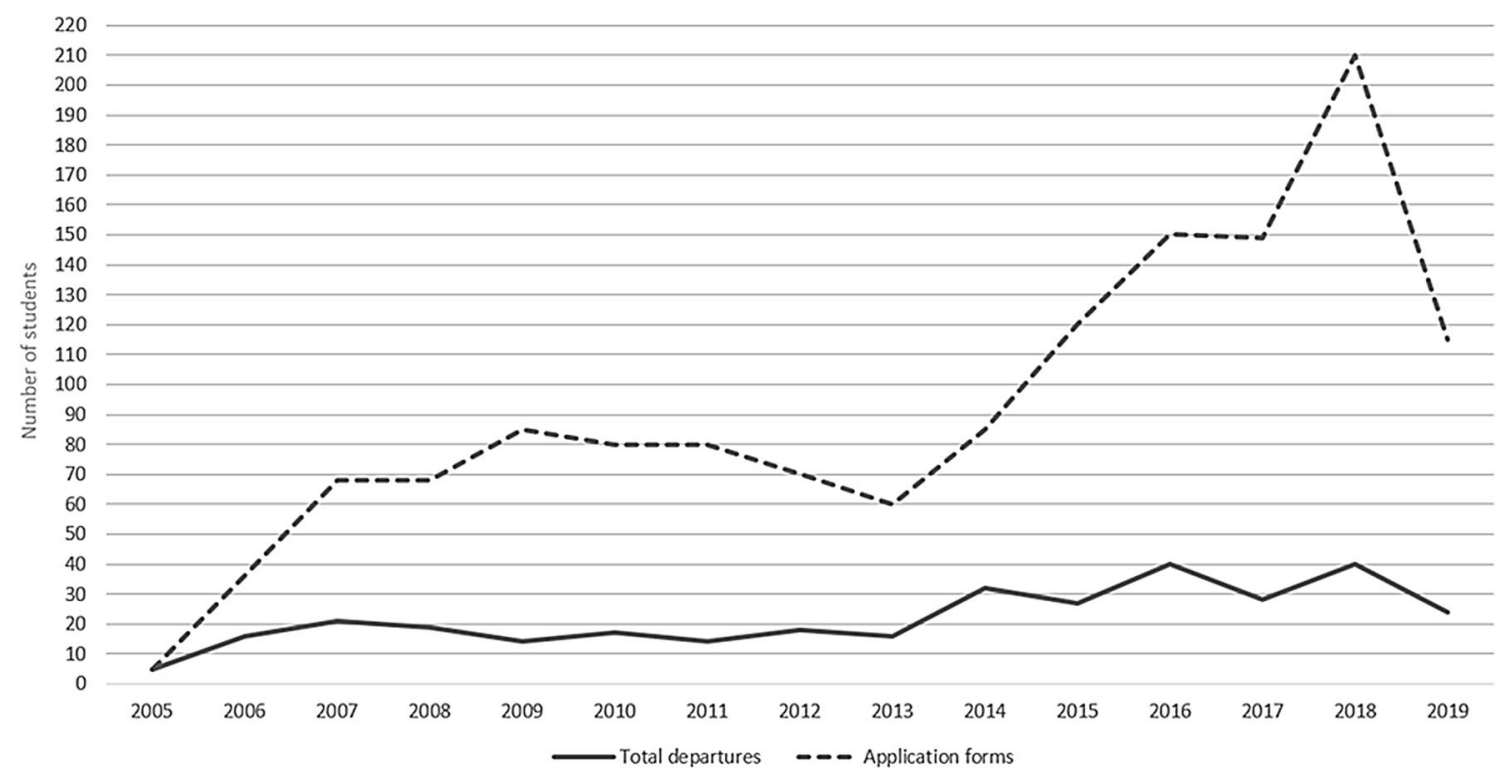

Fig. 1 Number of total applications and departures, period 2005-2019 


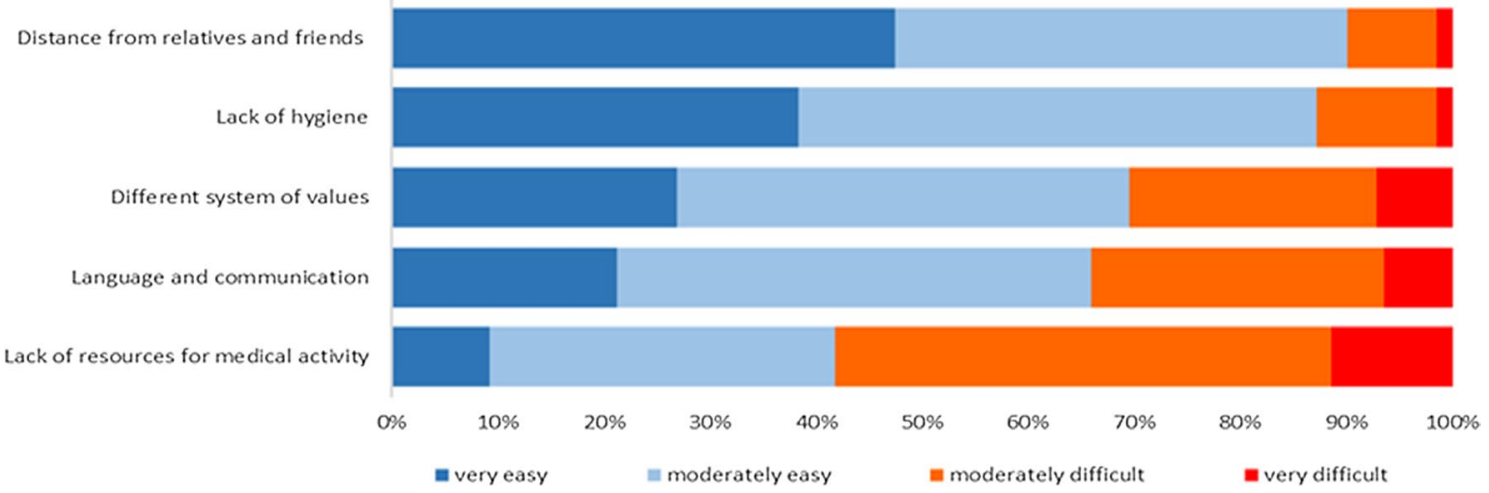

Fig. 2 Obstacles reported during the medical elective

The analysis of these obstacles in relation to the period of departure (2005-2015 versus 2016-2019) showed that the distance from family and friends was significant for the subjects who did the experience in the period 2005-2015 $(\mathrm{p}<0.05)$; language and communication $(\mathrm{p}<0.05)$ and lack of hygiene $(\mathrm{p}<0.05)$ were statistically significant for people in Tosamaganga than in Wolisso.

\section{Impact on Medical Studies, Clinical Approach and Future Professional Choices}

The African experience had a positive impact on the progress of the studies upon return, with an increase in determination and motivation in $65 \%$ and $70 \%$ of cases respectively. The majority report also an increase in creativity (55\%), whereas only $25 \%$ report an increase in the organisation of work.

The experience had positive influences on the future clinical approach of the students. Respondents say they have gained in terms of humanity ( $84 \%$ of subjects)and in resilience (83\%). The percentage of those who declare that they feel more courageous (73\%) and empathetic (72\%) is also significant. High percentages of subjects also declared a greater ability to collaborate (68\%) and an increase of patience $(62 \%)$, self-confidence $(61 \%)$, and respect for others $(59 \%)$. The analysis of these responses in relation to the period of departure, country of destination and clinical experience revealed no statistically significant differences. Seventy-one participants $(50 \%)$ reported that the experience had had an impact on their future career choices.

In the open question related to the impact of the experience on future professional choices, most of comments were related to the international cooperation as a whole:

I decided to undertake a post-graduate in international health cooperation.

I started to think of international health cooperation as a concrete possibility for the future.
I have decided to pursue a career as a cooperating doctor and that is what I am currently doing.

This experience has been useful for me to understand that working permanently in a developing country is not for me: however, this experience gave me a desire to return to Africa with more skills to share.

A substantial number of comments relate to the fact that experience influenced the choice of the specialisation:

I changed my mind ... and I decided to do anesthesia.

I chose to become a pediatrician.

I opted for a surgical specialty.

After this experience, I decided to take care of the health of migrants in Italy.

I have definitely chosen a career in pediatrics.

I became passionate about neonatology, which I had not considered before.

I saw how public health and hygiene are crucial topics in the management of health systems.

I want to work in the field of migration medicine.

Many also expressed the desire to repeat the experience.

I would like to spend part of my residency in Africa.

I would like to return with greater professionalism to be able to give a more concrete help

I would like to relive a similar experience.

Now I know I want to go back to Africa.

I have a desire to return to Africa for longer periods.

I am sure I will return to Africa for another international collaboration experience. 

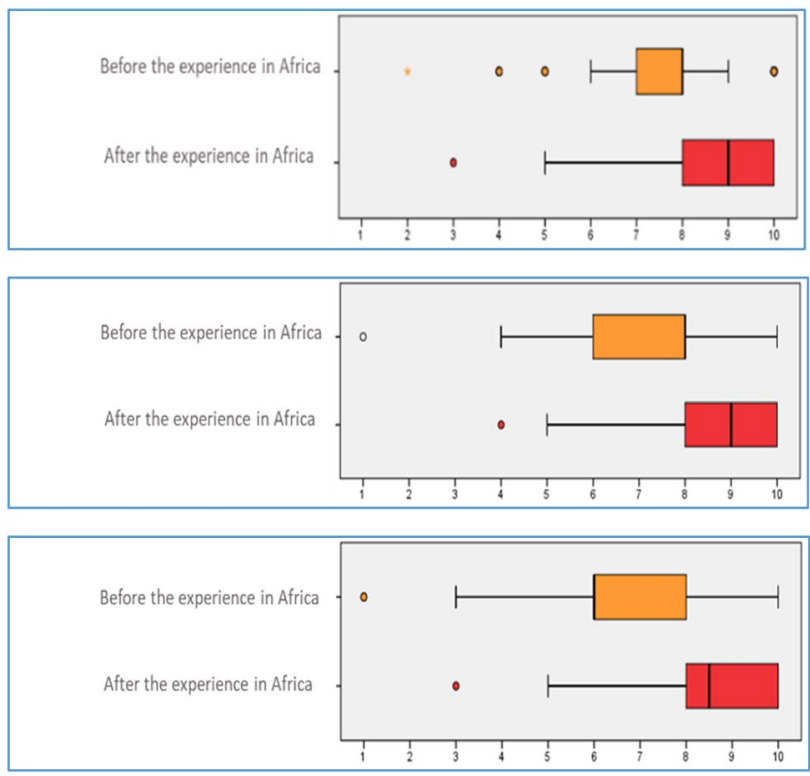

Fig. 3 Health inequalities (upper box), commitment to reduce the environment damage (intermediate box), and awareness of the wasting health resources (lower box) before and after the experience in Africa $(1=$ low; $10=$ high $)$

\section{Reflections}

This section explored how the experience had had an effect on students' interest in health inequalities, their commitment to reduce the environment damage, and their awareness of the wasting health resources, comparing pre and post-experience data (Fig. 3). All these pre-post differences result statistically significant $(\mathrm{p}<0.01)$. These changes were not affected by the destination or by the period of departure.

A further question explored how the clinical elective experience contributes to both personal and professional growth. On a scale of 1 to 10 (where $1=$ low and $10=$ high), $75 \%$ of respondents chose a score equal to or greater than 7 to describe their professional growth. The same percentage of respondents chose a score equal to or greater than 8 to describe their personal growth (Fig. 4).

The final questions revealed that the majority were willing to repeat the experience, with $51 \%$ saying definitely and $46 \%$ probably. Only $3 \%$ excluded this possibility. Of all respondents, $20 \%$ have already spent additional time in a medical setting in Africa. After the African experience, $66 \%$ of respondents say they have maintained some form of contact with DwA, participating in training, awareness and support activities of cooperation projects.

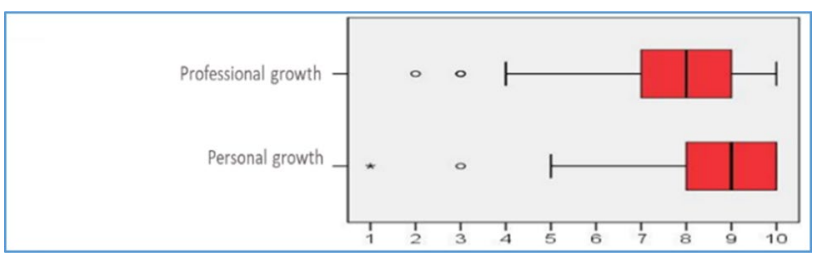

Fig. 4 Personal and professional growth before and after the experience in Africa $(1=$ low; $10=$ high $)$

\section{Discussion}

In this study nearly all students gave positive feedback about the overall experience. Most students were positively influenced personally and professionally, and said they were willing to repeat the experience. The two biggest difficulties reported are a lack of resources for the practice of the medical activities (although the students were not directly involved in diagnostic and therapeutic activities) and problems with communication. These obstacles are recognised elsewhere [37, 38]. Apparently, as observed by Mutchnick et al.[3], 'living in alternative social environments creates an educational experience unmatched in any textbook or classroom exercise'. Professionally, students declare that they have returned home with a greater sense of empathy towards patients, an augmented confidence in their clinical skills, and abetter appreciation of the importance of issues such as health inequalities. The experience also seems to influence the orientation of the students' careers, increasing the interest in public service. The students also report an increased awareness of problems concerning the use of resources. Similar results have been found in other studies [39-44].

Jeffrey et al. [45] carried out a literature review examining the potential role of international health electives in improving students' professional growth and career choices. Key findings from the review suggest that a medical elective experience gives opportunities for medical students to strengthen self-confidence in medical practices, increase knowledge of tropical diseases, gain a better awareness of environmental health and public health actions. In addition, medical electives seem to influence the career choices of medical students. The results of Jeffrey et al. are in line with the results of the present study, where the vast majority of students declare that the experience has had a positive impact on a personal level, and that the experience led them to reflect more deeply on future choices at post-graduated level.

The number of students doing a medical elective in a LMICs has progressively increased over the years [11]. It is also confirmed by the present study. In the first 5 years of the project (2005-2009) there was each year an average of 52 applications. This increased to 148 in the last 5 years of the 
project (2015-2019). During the course of the project there was a corresponding increase in the number of departures, from an average of 15 over the first five years to 32 over the final five years. It should be noted that increase occurred despite the fact that travel and accommodation costs are incurred directly by students and that the recognition of experience with credits does not seem to be widespread in many universities.

Although educational and other potential benefits offered by elective periods in LMICs are recognised, the experience presents a number of challenges, with a danger 'of doing more harm than good' [38]. For instance, electives may falsely raise student expectations, and put strain on local human resources. As observed by Ackerman [46], 'on-site supervisors, the back-bone of most electives, are only possible with a reciprocal, long-term relationship either through a local university and medical school, a Nongovernmental Organization (NGO), or an International Nongovernmental Organization (INGO) working in the area. The educators must ensure that the host organization is appropriately integrated into the community and that community goals are at the forefront'. Willottet al. [47] highlights that, 'even if sending institutions oblige that students pre-prepare objectives and receive guidance about what is expected of them during elective, effective monitoring of students' activities on the ground is nearly impossible'. In addition, he observed that, 'students frequently want to be able to decide for themselves where they go and how they spend their electives, but this may not be what is best for hosting institutions, nor for global health more generally'. As pointed out by Edwards and colleagues [14], a major concern regarding medical electives is that students may practice, 'beyond their competence, to their own and their patients' detriment. This may be more common in developing countries where supervision is scant and students may assume that limited health care resources justify their adopting roles or performing procedures which would be restricted to fully trained staff at home'.

These reflections highlight the benefits of an experience like the WP, which is organised and implemented by an NGO with long-term working relationships with the African populations and is well integrated into the community. The project is carried out in health facilities where DwA staff have been working for many years. Having well-known locations for electives reduces the potential risks connected with this type of experience, and better ensures a satisfactory level of supervision, the lack of which being a serious problem in many similar experiences $[38,48]$.

The project described herein was possible thanks to the initiative and collaboration of an NGO and a medical students' organisation, without any direct support form a university. To the best of our knowledge, only a small number of Italian universities facilitate pre-graduate medical elective experiences in LMICs. The WP has enabled pre-graduate medical elective experiences to students from 30 different Italian universities (there are 43 faculties of medicine in Italy). The WP therefore, seems to be making up for the lack of international experience in LMICs offered by universities.

Pre-graduate medical electives are often organised by individual universities. It is therefore not straightforward to make comparisons between countries. However, it seems possible to make some observations. In comparison with many European Union Member States (and associated countries), it might be said that the Anglo-Saxon countries have a more robust and structured tradition of medical elective, with the development of specific guidelines and the promotion more global health opportunities for medical students[11, 49-52]. For example, in Australia electives are a compulsory component of all medical curricula. They usually last 2 to 8 weeks, and take place either in Australia or overseas, including LMICs [11]. In the UK approximately $90 \%$ of medical students undertake medical electives, with $44 \%$ of them doing so in LMICs [53]. However, positive experiences have also been enabled in Europe. A study from Switzerland (related to the year 2009-2010) showed that from 106 medical students who underwent a medical elective, $50 \%$ went to a LMIC [54]. In Switzerland, undergraduate medical education is provided at all five medical universities, each of which recognizes time spent away by awarding academic credit [54]. In Ireland there is a certain level of recognition of international medical electives by all medical schools [38]. A study from Germany (Munchen University) found that $17 \%$ of pre-graduate medical students undertake medical electives in LMICs [55].

However, at post-graduate level, the situation in Italy seems to be in better shape. A number of initiatives appear to be going in the right direction, including agreements between DwA and some Italian universities, concerning collaboration on global health and medical experience and operational research in Africa [56].

We should note that before medical schools allocate substantial resources for international medical education, more rigorous evaluation of the effectiveness of medical elective experience is needed to demonstrate whether they add value to medical training [49], and what impact they may have on the communities and institutions involved [57]. Long-term follow-ups of elective participants after medical school in relation to their career choices (e.g., type of medical practice, career developed in public or private sectors) can provide more convincing arguments to medical schools that investing in medical electives will pay dividends in the long run [45]. 


\section{Conclusion}

Although common to other experiences of this type, it cannot be overlooked that the project has several shortcomings. The experience does not last long, contacts with local communities are limited, and it is difficult to estimate their real impact. The supervision of students in the field can and needs to be strengthened. Although in ways, it is encouraging, feedback from local supervisors and local communities it is not systematically evaluated. The students interviewed did electives on sites only within one region: sub-Saharan Africa. Therefore, the findings presented here cannot automatically be applied to electives in other LMICs. The study utilised a self-administered questionnaire, without any corroborating measures available to address potential selfreporting bias (e.g., clinical skills performance testing, feedback from hosting institutions, etc.). The study did not have a control group. Finally, although the majority of questionnaires were completed by those who had the experience in the last 3 years (2016-2019), there was significant variation in the time elapsed between the experience in Africa and the administration of the questionnaire. Future objectives of the WP is to improve the pre-departure training (e.g. offering guidelines for pre-departure), to be developed more in partnership with receiving institutions [58]. Another future objective is to improve the selection procedure (e.g. through mini interviews as a pre-departure tool) [59]. Additional aims are to have structured feedback from local supervisors and local communities, to better quantify the impact of the elective experience through questionnaires administered before and after departure, and to develop additional outcome measures (other than self-reports) focusing on provider behaviour, clinical knowledge, and quality of patient care [15].

The mission of the medical school should be not only to train good clinicians, but also to be more community oriented, reconciling individual and community health needs $[53,60]$.Cross-cultural exchanges like medical electives have the potential to help medical students become culturallyaware and globally-competent physicians [3, 61, 62]. Despite its limitations, the present study provides evidence that international electives in LMICs develop students' idealism about their role as future physicians. As noted by Godkin and Savageau, 'even if international electives do nothing more than preserve idealistic values, they have served a useful purpose' [41].

Supplementary Information The online version contains supplementary material available at https://doi.org/10.1007/s10900-021-01045-5.

Acknowledgements Not applicable.

Author Contributions GP, $\mathrm{CDB}$ and $\mathrm{CC}$, contributed to the conception and design of the study. $\mathrm{CC}, \mathrm{CDB}, \mathrm{MB}$, and $\mathrm{AL}$ contributed to data acquisition. GQ provided the literature review.NP provided the statistical analysis. All authors contributed to the data analysis and interpretation, and the drafting and revision of the article. All authors approved the final manuscript for publication.

Funding No funding was obtained for this study.

Data Availability The datasets used and/or analysed during the current study are available from the corresponding author on reasonable request. The questionnaire used in the study was developed specifically for this study (in Italian). An English version is available as a supplementary file.

Code Availability Not applicable.

\section{Declarations}

Conflict of interest The authors declare that they have no competing interests.

Ethical Approval This study was approved by the Ethics Committee of DwA-CUAMM (reference number: 2521). All potential participants were sent brief details of the study and offered a more detailed standard information sheet. The data collection was carried out in accordance with relevant guidelines and regulations.

Consent to Participate The informed consent obtained from study participants was in a written format.

Consent for Publication Not applicable.

\section{References}

1. Editorial. (1969). Overseas medical aid. Journal of the America Medical Association, 209(10), 1521-1522.

2. James, H. (2020). Could coronavirus bring about the 'waning of globalization'? World Economic Forum. Retrieved November 9, 2021, from https://www.weforum.org/agenda/2020/03/globalizat ion-coronavirus-covid19-epidemic-change-economic-political

3. Mutchnick, I. S., Moyer, C. A., \& Stern, D. T. (2003). Expanding the boundaries of medical education: Evidence for cross-cultural exchanges. Academic Medicine, 78(10 Suppl), S1-S5.

4. Banerjee, A., Banatvala, N., \& Handa, A. (2011). Medical student electives: Potential for global health? The Lancet, 377(9765), 555.

5. Editorial. (1993). The overseas elective: Purpose or picnic? The Lancet, 342(8874), 753-754.

6. Kumwenda, B., Royan, D., Ringsell, P., \& Dowell, J. (2014). Western medical students' experiences on clinical electives in sub-Saharan Africa. Medical Education, 48(6), 593-603.

7. Thompson, M. J., Huntington, M. K., Hunt, D. D., Pinsky, L. E., \& Brodie, J. J. (2003). Educational effects of international health electives on U.S. and Canadian medical students and residents: A literature review. Academic Medicine, 78(3), 342-347.

8. Ramsey, A. H., Haq, C., Gjerde, C. L., \& Rothenberg, D. (2004). Career influence of an international health experience during medical school. Family Medicine, 36(6), 412-416.

9. Drain, P. K., Primack, A., Hunt, D. D., Fawzi, W. W., Holmes, K. K., \& Gardner, P. (2007). Global health in medical education: A call for more training and opportunities. Academic Medicine, 82(3), 226-230.

10. Drain, P. K., Holmes, K. K., Skeff, K. M., Hall, T. L., \& Gardner, P. (2009). Global health training and international clinical 
rotations during residency: Current status, needs, and opportunities. Academic Medicine, 84(3), 320-325.

11. Law, I. R., Worley, P. S., \& Langham, F. J. (2013). International medical electives undertaken by Australian medical students: Current trends and future directions. Medical Journal of Australia, 198(6), 324-326.

12. Umoren, R. A., Gardner, A., Stone, G. S., Helphinstine, J., Machogu, E. P., Huskins, J. C., et al. (2015). Career choices and global health engagement: 24-year follow-up of U.S. participants in the Indiana University-Moi University elective. Healthcare, 3(4), 185-189.

13. Kleinman, A. (2010). Four social theories for global health. The Lancet, 375, 1518-1519.

14. Edwards, R., Piachaud, J., Rowson, M., \& Miranda, J. (2004). Understanding global health issues: Are international medical electives the answer? Medical Education, 38(7), 688-690.

15. Murdoch-Eaton, D., \& Green, A. (2011). The contribution and challenges of electives in the development of social accountability in medical students. Medical Teacher, 33(8), 643-648.

16. Johnston, N., Sandys, N., Geoghegan, R., O’Donovan, D., \& Flaherty, G. (2018). Protecting the health of medical students on international electives in low-resource settings. Journalof Travel Medicine. https://doi.org/10.1093/jtm/tax092

17. Dharamsi, S., Osei-Twum, J. A., \& Whiteman, M. (2011). Socially responsible approaches to international electives and global health outreach. Medical Education, 45(5), 530-531.

18. Crump, J. A., \& Sugarman, J. (2008). Ethical considerations for short-term experiences by trainees in global health. Journal of the America Medical Association, 300(12), 1456-1458.

19. Roebbelen, E., Dorman, K., Hunter, A., Kraeker, C., O'Shea, T., \& Bozinoff, N. (2018). "They will come to understand": Supervisor reflections on international medical electives. Teaching and Learning in Medicine, 30(4), 377-385.

20. Crump, J. A., \& Sugarman, J. (2010). Ethics and best practice guidelines for training experiences in global health. American Journal of Tropical Medicine and Hygiene, 83(6), 1178-1182.

21. Keller, R. C. (2006). Geographies of power, legacies of mistrust: Colonial medicine in the global present. Historical Geography, $34,26-48$

22. Horton, R. (2013). Offline: Is global health neo-colonialist? Lancet, 382, 1690.

23. Eichbaum, Q. G., Adams, L. V., Evert, J., Ho, M. J., Semali, I. A., \& van Schalkwyk, S. C. (2021). Decolonizing global health education: Rethinking institutional partnerships and approaches. Academic Medicine, 96(3), 329-335.

24. Herzig van Wees, S., \& Holmer, H. (2020). Global health beyond geographical boundaries: Reflections from global health education. BMJ Global Health, 5(5), e002583.

25. Harvard Chan student committee for the decolonization of public health. (2019). Decolonizing global health conference 2019. Retrieved November 9, 2021, from https://www.hsph.harvard. edu/decolonizingglobal-health-so/

26. Ventres, W. B., \& Wilson, B. K. (2020). Rethinking goals: Transforming short-term global health experiences into engagements. Academic Medicine, 95(1), 32-36.

27. Smith, J. K., \& Weaver, D. B. (2006). Capturing medical students' idealism. Annalsof Family Medicine, 4(Suppl 1), S32-S60.

28. Dowell, J., \& Merrylees, N. (2009). Electives: Isn't it time for a change? Medical Education, 43(2), 121-126.

29. Italian Medical Students Association (SISM). (2021). Wolisso Project website. Retrieved November 9, 2021, from http://wolis so.sism.org/

30. Italian Medical Students Association (SISM). (2021). SISM website. Retrieved November 9, 2021, from https://nazionale. sism.org/
31. Doctors with Africa-CUAMM (DwA-CUAMM). (2021). DwA website. Retrieved November 9, 2021, from https://doctorswit hafrica.org/

32. Doctors with Africa-CUAMM. (2015). Strategic Plan 2016-2030. Retrieved November 9, 2021, from https://www.mediciconlafrica. org/en/who-we-are/mission/strategic-plan-2016-2030/

33. International Federation of Medical Students Associations (IFMSA). (2021). IFMSA website. Retrieved November 9, 2021, from https://ifmsa.org/

34. Doctors with Africa-CUAMM (DwA-CUAMM). Annual report 2019. (2020). CUAMM website. Retrieved November 9, 2021, from https://www.mediciconlafrica.org/wp-content/uploads/2020/ 07/CUAMM_annual_report_2019_eng_web-1.pdf

35. Doctors with Africa-CUAMM (DwA-CUAMM). (2021). Global health: Ideas on education and public awareness website. Retrieved November 9, 2021 from http://www.educationglobal health.eu/en/

36. Doctors with Africa-CUAMM (DwA-CUAMM). (2021). Italian medical students association (SISM). Guest book website. Retrieved November 9, 2021 from http://www.educationglobal health.eu/it/blog

37. Elit, L., Hunt, M., Redwood-Campbell, L., Ranford, J., Adelson, N., \& Schwartz, L. (2011). Ethical issues encountered by medical students during international health electives. Medical Education, 45(7), 704-711.

38. O'Donnell, P., McAuliffe, E., \& O'Donovan, D. (2014). Unchallenged good intentions: A qualitative study of the experiences of medical students on international health electives to developing countries. Human Resources for Health, 12, 49.

39. Haloburdo, E. P., \& Thompson, M. A. (1998). A comparison of international learning experiences for baccalaureate nursing students: Developed and developing countries. Journal of Nursing Education, 37(1), 13-21.

40. Haq, C., Rothenberg, D., Gjerde, C., Bobula, J., Wilson, C., Bickley, L., et al. (2000). New world views: Preparing physicians in training for global health work. Family Medicine, 32(8), 566-572.

41. Godkin, M. A., \& Savageau, J. A. (2001). The effect of a global multiculturalism track on cultural competence of preclinical medical students. Family Medicine, 33(3), 178-186.

42. Esfandiari, A., Drew, C. R., Wilkerson, L., Gill, G., \& Drew, C. R. (2001). An international health/tropical medicine elective. Academic Medicine, 76(5), 516.

43. Kollar, S. J., \& Ailinger, R. L. (2002). International clinical experiences: Long-term impact on students. Nurse Educator, 27(1), $28-31$.

44. Stys, D., Hopman, W., \& Carpenter, J. (2013). What is the value of global health electives during medical school? Medical Teacher, 35(3), 209-218.

45. Jeffrey, J., Dumont, R. A., Kim, G. Y., \& Kuo, T. (2011). Effects of international health electives on medical student learning and career choice: Results of a systematic literature review. Family Medicine, 43(1), 21-28.

46. Ackerman, L. K. (2010). The ethics of short-term international health electives in developing countries. Annals of Behavioral Science and Medical Education, 16, 40-43.

47. Willott, C., Khair, E., Worthington, R., Daniels, K., \& Clarfield, A. M. (2019). Structured medical electives: A concept whose time has come? Global Health, 15(1), 84.

48. Watson, D. A., Cooling, N., \& Woolley, I. J. (2019). Healthy, safe and effective international medical student electives: A systematic review and recommendations for program coordinators. Tropical Diseases, Travel Medicine and Vaccines, 5, 4.

49. Wiskin, C., Barrett, M., Fruhstorfer, B., \& Schmid, M. L. (2018). Recommendations for undergraduate medical electives: A UK consensus statement. Medical Education, 52(1), 14-23. 
50. Lumb, A., \& Murdoch-Eaton, D. (2014). Electives in undergraduate medical education: AMEE guide no. 88. Medical Teacher, 36(7), 557-572.

51. Watterson, R., Matthews, D., Bach, P., Kherani, I., Halpine, M., \& Meili, R. (2015). Building a framework for global health learning: An analysis of global health concentrations in Canadian medical schools. Academic Medicine, 90(4), 500-504.

52. McCool, J., Curtis, E., MacCormick, A. D., Cavadino, A., Smith, M., \& Bagg, W. (2019). Medical electives: Exploring the determinants of placement and access variables between 2010 and 2016 at the University of Auckland. BMC Medical Education, 19(1), 398.

53. Miranda, J. J., Yudkin, J. S., \& Willott, C. (2005). International health electives: Four years of experience. Travel Medicineand Infectious Disease, 3(3), 133-141.

54. Dupuis, M., \& Schirlo, C. (2012). The clinical electives year in undergraduate medical training in Switzerland: An overview. Journal of Evidence and Quality in Health Care, 106(2), 85-91.

55. Störmann, S., \& Angstwurm, M. W. (2018). What do international health electives and state examination scores have in common?A cohort study to compare the results of written medical licensing examinations with the participation in international health electives during the final year of undergraduate medical education in Germany. GMS Journal for Medical Education, 35(5), 54.

56. Da Dalt, L., Putoto, G., Carraro, D., Gatta, A., Baraldi, E., \& Perilongo, G. (2014). International child health elective for pediatric residents. Italian Journalof Pediatrics, 40, 13.

57. Renaud-Roy, E., Bernier, N., \& Fournier, P. (2020). Host perspective on academic supervision, health care provision and institutional partnership during short-term electives in global health. Medical Education, 54(4), 303-311.

58. Kalbarczyk, A., Nagourney, E., Martin, N. A., Chen, V., \& Hansoti, B. (2019). Are you ready? A systematic review of pre-departure resources for global health electives. BMC Medical Education, $19(1), 166$.

59. Satterfield, C. A., Dacso, M. M., \& Patel, P. (2018). Using multiple mini interviews as a pre-screening tool for medical student candidates completing international health electives. Medical Education Online, 23(1), 1483694.

60. Boelen, C. (1995). Prospects for change in medical education in the twenty-first century. Academic Medicine, 70(7), S21-S31.

61. Shaywitz, D. A., \& Ausiello, D. A. (2002). Global health: A chance for Western physicians to give-and receive. American Journal of Medicine, 113(4), 354-357.

62. Quaglio, G. L., Bortolozzo, M., Di Benedetto, C., Lupato, A., Cavagna, C., \& Putoto, G. (2021). Medical electives in Sub-saharan Africa: A 14-years student/NGO-driven Initiative. Research Square. Retrieved November 9, 2021 from https://assets.resea rchsquare.com/files/rs-96220/v1/6dc9ebf2-6b7a-4547-b21d$4 \mathrm{c} 31 \mathrm{~b} 1 \mathrm{~d} 68 \mathrm{~d} 6 \mathrm{e} \cdot \mathrm{pdf} ? \mathrm{c}=1631858813$

Publisher's Note Springer Nature remains neutral with regard to jurisdictional claims in published maps and institutional affiliations. 